\title{
Prevalence and clinical relevance of extra-cardiac findings at cardiac magnetic resonance imaging
} \author{
Christina Unterberg-Buchwald ${ }^{2}$, Jan M Sohns ${ }^{1}$ \\ From 16th Annual SCMR Scientific Sessions \\ San Francisco, CA, USA. 31 January - 3 February 2013
}

Wieland Staab ${ }^{1 *}$, Alexander Schwarz ${ }^{1}$, Jan Menke ${ }^{1}$, Judith E Spiro ${ }^{1}$, Paul A Zwaka ${ }^{1}$, Joachim Lotz'

\section{Background}

The aim of this study was to assess the incidence of extra-cardiac findings in patients undergoing clinical cardiac magnetic resonance imaging (CMRI) of the heart including surrounding structures and to determine the influence of those findings on patient's management.

\section{Methods}

$\mathrm{N}=854$ patient studies (median age $58 \pm 12$ years, male 63\%) were included and examined by 1.5 Tesla (T) MR to primarily analyze the cardiac anatomy and secondly the surrounding structures. Extra-cardiac findings were classified as significant (Group A) if they were recommended to additional diagnostics or therapeutical interventions and as non-significant if there was no influence on patient's management (Group B).

\section{Results}

631 patient studies were free of any kind of extra-cardiac pathologies. In the remaining cases, 286 extra-cardiac findings were examined. There were $\sim 0.33$ extracardiac findings per patient. 49 were defined as significant (Group A) and 237 as nonsignificant findings (Group B). The most common Group A findings were suspicious pulmonary nodules or masses $>4 \mathrm{~mm}$ diameter $(n=14)$ and aortic aneurysms $(n=5)$. In Group B, most of the findings were hepatic cysts or hemangiomas $(n=50)$, followed by renal cysts $(n=47) .8$ malignancies were certainly observed. The most frequent indication for CMRI was evaluation of cardiac stress ischemia $(\mathrm{n}=501,59 \%)$.

${ }^{1}$ Radiology, University Medical Center Georg-August-University, Göttingen, Germany

Full list of author information is available at the end of the article

\section{Conclusions}

Extra-cardiac findings in clinical CMRI are common in patients referred to CMRI (26\%). Radiologists and cardiologists have to be aware of relevant extra-cardiac findings which might require additional diagnostics or treatment. There is an importance of paying appropriate attention to structures outside of the heart.

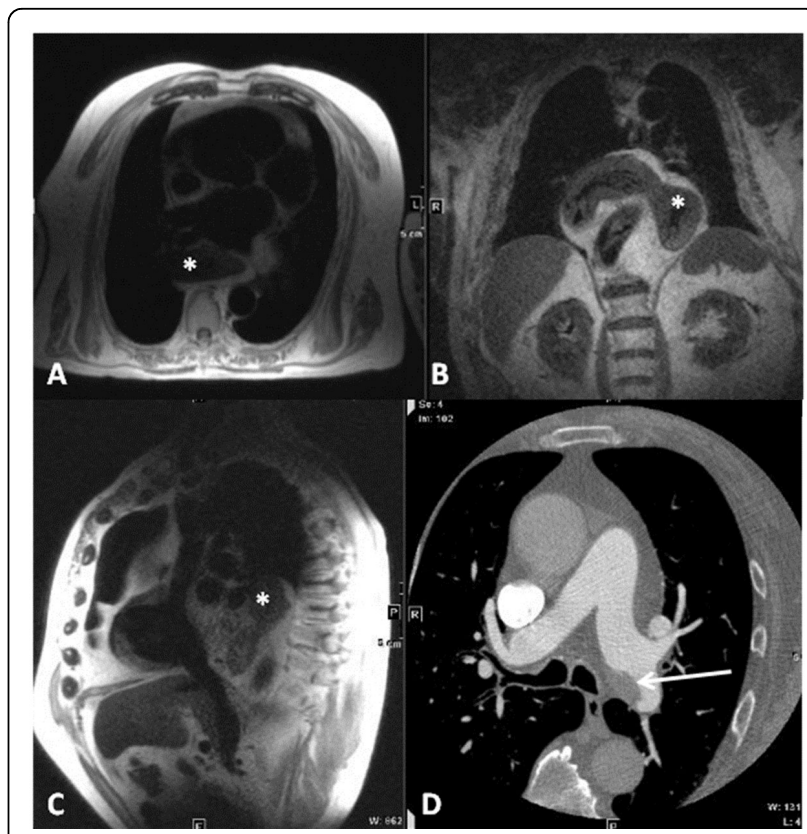

Figure 1 Gastric herniation and angiosarcoma primarily found at CMRI. In a 77 years old male, CMRI primarily detected a thoracic gastric herniation (white stars, A: transversal, Haste, TR 800, TE 46; B: coronal, Haste, TR 800, TE 46; and C: parasagittal, Haste, TR 800, TE 46). An angiosarcoma of the left pulmonary artery was seen in a contrast medium enhanced follow-up thoracic CT scan in the same patient (D: white arrow, axial, 64-slices CT). Recommendation for additional diagnostics was given. Findings were defined as "significant". 


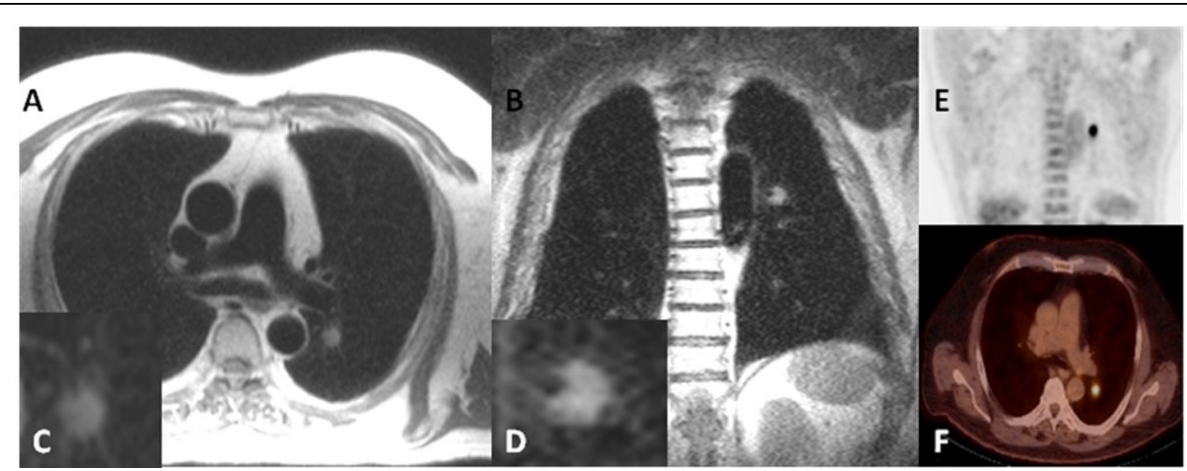

Figure 2 Lung cancer found at CMRI. In a 71 years old patient, CMRI incidentally detected a pulmonary lesion in the left upper lung which was visible on transversal (A: Haste, TR 800, TE 43) and coronal views (B: Haste, TR 650, TE 42). Magnifications are shown in the insets C and D. This "significant" finding was confirmed by a subsequent 18F-FDG PET/CT (E: coronar, F: axial). At histology a bronchial carcinoma was diagnosed and treated. Size $4 \times 3 \mathrm{~cm}$.

\section{Funding}

None.

\section{Author details}

${ }^{1}$ Radiology, University Medical Center Georg-August-University, Göttingen, Germany. ${ }^{2}$ Cardiology and Pneumology, University Medical Center GeorgAugust-University, Göttingen, Germany.

Published: 30 January 2013

doi:10.1186/1532-429X-15-S1-P267

Cite this article as: Staab et al:: Prevalence and clinical relevance of extra-cardiac findings at cardiac magnetic resonance imaging. Journal of Cardiovascular Magnetic Resonance 2013 15(Suppl 1):P267.

\section{Submit your next manuscript to BioMed Central} and take full advantage of:

- Convenient online submission

- Thorough peer review

- No space constraints or color figure charges

- Immediate publication on acceptance

- Inclusion in PubMed, CAS, Scopus and Google Scholar

- Research which is freely available for redistribution

Submit your manuscript at www.biomedcentral.com/submit 